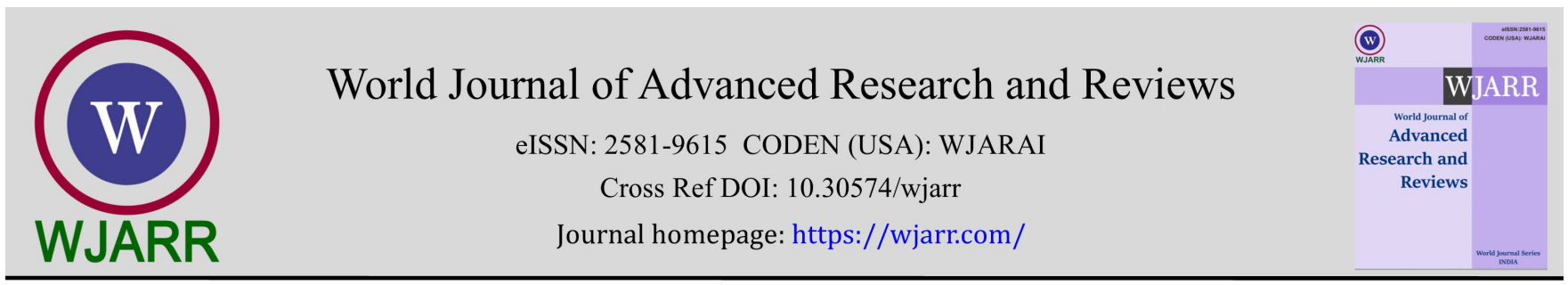

(RESEARCh ARTICLE)

\title{
Prevalence and determinants of induced abortion among reproductive-aged women in Aykel town North West, Ethiopia: A community-based cross-sectional study
}

\author{
Agerie Mengistie Zeleke* \\ Department of Midwifery, School of Public Health, Teda Health Science College, Gondar, Ethiopia.
}

World Journal of Advanced Research and Reviews, 2021, 12(02), 032-041

Publication history: Received on 30 September 2021; revised on 30 October 2021; accepted on 01 November 2021

Article DOI: https://doi.org/10.30574/wjarr.2021.12.2.0501

\begin{abstract}
Objective: This study aimed to assess the prevalence and determinants of induced abortion among women of the reproductive age group in Aykel town North West, Ethiopia.

Method: Community based cross-sectional study was employed in Aykel town North West Ethiopia, from August to September 2018. A systematic random sampling technique was used to recruit a total of 422 reproductive-aged women during the study period. Binary logistic regression model fitted to identify factors associated with induced abortion. Adjusted odds ratio with $95 \% \mathrm{CI}$ used to explore the strength of association between outcome and independent variables.

Result: The prevalence of induced abortion was 14.5\% with 95\% CI (11.2 to 18.17). Age group of 15-24 years [AOR=3.10, 95\%CI (1.116-8.543)], pregnancy status unwanted [AOR=3.1; 95\%CI (1.292-7.322], not ever used contraceptive $[\mathrm{AOR}=3.96 ; 95 \% \mathrm{CI}(1.612-9.709)]$, parity [AOR= 0.37, 95\%CI (0.164-0.823)], knowing induce abortion complication $[\mathrm{AOR}=2.24,95 \% \mathrm{CI}(1.104-4.551]$,partner primary educational level $[\mathrm{AOR}=3.68,95 \% \mathrm{CI}(1.082-12.528)]$ were determinants of induced abortion among reproductive age women.

Conclusions: This study revealed that the magnitude of induced abortion was high. Younger age, pregnancy status unwanted, had not ever used contraceptive, knowing induced abortion complication, and partner education level was positively associated with induced abortion. In contrast, parity negatively associated with induced abortion. Therefore, induce abortion intervention like contraception provisions need to focus young age group.
\end{abstract}

Keywords: Induced abortion; Determinants; Reproductive-age women; Aykel town

\section{Introduction}

Induced abortion is defined as the intentional termination of the pregnancy for medical or any other reason before it reaches viability[1]. Induced abortion is performed due to provocation from the outside by intentional terminating and unwanted pregnancy[2]. Globally, one in five pregnancies ends with an induced abortion; and it was one of the direct causes of maternal death in the world[3-5]. Unsafe abortion is the leading cause of maternal deaths and accounted for $13 \%$ of all maternal deaths of which, $25 \%$ of maternal deaths occurred in developing countries[4].Globally, there were an estimated 56 million abortions according to the United Nation Development Program (UNDP)annual report[4].

Women who failed to use contraceptives and got conceived may practice induced abortion as a means of family planning for limiting and spacing birth[6]. Unintended pregnancy the major contributing factor for induced abortion; about 38 million unintended pregnancies occur each year globally[7]. Induced abortion has negative health consequences such

${ }^{*}$ Corresponding author: Agerie Mengistie Zeleke; E-mail: ageriemengistie@gmail.com

Department of Midwifery, School of Public Health, Teda Health Science College, Gondar, Ethiopia.

Copyright (C) 2021 Author(s) retain the copyright of this article. This article is published under the terms of the Creative Commons Attribution Liscense 4.0. 
as infertility, uterine inconsistency, and psychosocial problems [8-13]. Due to different interventions in developed countries abortion rates have decreased by $41 \%$ over time. However, in developing countries, the rate of abortion remained unchanged at 37 abortions per 1000 women for a quarter of a century.

Ethiopia one of the countries with the highest maternal mortality with 412 deaths per 100,000 live births EDHS 2016 report[14]. Moreover unsafe and induced abortion is one of the leading causes of pregnancy-related maternal deaths. Ethiopia has restrictive abortion law indicated under certain preconditions such as, case of rape, incest pregnancy, medical conditions which might endanger mother or her child's life [15]. Ethiopia government has made tremendous efforts to decrease maternal mortality ration through expanding health facilities and providing post-abortion care in most health facilities.

Different factors associated with induced abortion like women's economic status, educational level, lack of knowledge,and access to family planning methods [6]. However, magnitude and predictors of induced abortion were not noticeably defined and interventions were not based on systematic evidence into possible factors of the fundamental practice in the study area.

Therefore, assessing the prevalence of abortion and associated factors among women reproductive age groups in the study area is very important to improve maternity services and there by reducing maternal death through providing health promotion, education, and counseling about complications of induced abortion and availability of family planning service.

\section{Methods}

A community-basedcross-sectional study was conducted from August to September 2018 in Aykel town Northwest, Ethiopia. The study setting Aykel town, which is located in the northwest part of Ethiopia and far about $60 \mathrm{~km}$ from Gondar town and $788 \mathrm{~km}$ from the capital city of Ethiopia. The town has two kebele with an estimated population of 20,738. According to district health office 2018 report, the town has, one district hospital, one health center, six private clinics and one NGO(World vision), which have theirown contribution for reproductive health abortion care and postabortion service.

All women of the reproductive age group in Aykel town were the source and study population. Women who reside in the town for at least six months and available during the data collection period were eligible for the study. Those patients who were unable to hear, mentally disabled, seriously sickand women who had known infertility were excluded from the study.

The required sample size of the study participant was determined by using single population proportion formula by considering the following assumptions the total sample size for this study is calculated as The sample size was calculated based on the following assumptions: assuming similar to a research done in Kenya with the prevalence of induced abortion $(p=48 \%$ ) [13], $Z=1.96$ at 95\% confidence interval, $d=$ the level of precision (0.05), and non-response rate = $10 \%$; then final total sample size for this study became $=422$. In the town there were 4,894 households with eligible women. Systematic random sampling technique was used to select the final samples. When selected household had than one reproductive aged woman, the final sample selected using lottery method.

The data collection tool initially prepared in English and translated to the local Amharic language. Data collected through the interviewer-administered questionnaire. Three female diploma midwife data collectors and one supervisor were recruited and trained for the data collection process by the principal investigator for one day. The data collection tool questionnaire was pretested in the Gondar Teda Keble. All collected data checked for completeness by the principal investigator and supervisor.

Induced abortion was the response variable, whereas socio-demographic (age, place of residence, educational level, religion, marital status), reproductive characteristics (parity, gravidity, and mode of delivery) and family planning service-related characteristics like access of family planning services, quality of family planning service, a distance of health facility Health provider factor Knowledge of women about services were independent variables.

The collected data were edited, coded, and cleaned up manually before entered into the computer, then information from questioners was enteredinto computer software called EPI-INFO version 7 and exported into SPSS version 20 for analysis. Descriptive summary measures like mean median, proportion computed. Tables and graphs used to present data. The binary logistic regression model was fitted to identify factors associated with induced abortion. Crude and adjusted odds ratio (OR) with $95 \%$ CI was used to describe the strength of association between the outcome and 
predictor variables. Variables with a p-value of less than 0.05 in the multivariable model were considered as significant determinants of induced abortion.

\section{Results}

\subsection{Socio-demographic characteristics of the study participants}

A total of 422 respondents were recruited and interviewed with a response rate of $100 \%$.The median age of respondents was 26(Inter-quartile range: 22-30) years. Among all participants were urban dwellers and the majority 329(78\%) of study participants were married. Regarding educational status $(24.6 \%)$ of respondents was unable to read and write. Most of $(88.4 \%)$ participants were orthodox religion followers. Nearly half $(46.4 \%)$ reproductive age groups were housewives and 104 (24.6\%) earned monthly income 5001-1000 Ethiopian birr (Table.1).

Table 1 Socio demographic characteristic of women reproductive age in Aykel town North West Ethiopia, 2018 (n=422)

\begin{tabular}{|c|c|c|c|}
\hline Characteristics & Category & Frequency & Percentage (\%) \\
\hline \multirow[t]{3}{*}{ Age } & $15-24$ & 150 & 35.5 \\
\hline & $24-34$ & 214 & 50.7 \\
\hline & $\geq 35$ & 58 & 13.7 \\
\hline \multirow[t]{2}{*}{ Marital status } & Married & 329 & 78 \\
\hline & Single & 93 & 22 \\
\hline \multirow[t]{5}{*}{ Education Status } & Unable to read and write & 104 & 24.6 \\
\hline & Able to read and write & 81 & 19.2 \\
\hline & Primary school & 63 & 14.9 \\
\hline & Secondary school & 76 & 18.0 \\
\hline & College and above & 98 & 23.2 \\
\hline \multirow[t]{2}{*}{ Religion } & Orthodox & 373 & 88.4 \\
\hline & Muslim & 49 & 11.6 \\
\hline \multirow[t]{3}{*}{ Ethnicity } & Amhara & 210 & 49.8 \\
\hline & Qimant & 203 & 48.1 \\
\hline & Other & 9 & 2.1 \\
\hline \multirow[t]{5}{*}{ Employment status } & housewife & 196 & 46.4 \\
\hline & Employed & 103 & 24.6 \\
\hline & Merchant & 70 & 16.2 \\
\hline & Student & 50 & 11.8 \\
\hline & Other & 2 & 0.5 \\
\hline \multirow[t]{2}{*}{ Monthly income (ETB) } & $\geq 1000$ & 227 & 53.1 \\
\hline & $<1000$ & 198 & 46.9 \\
\hline
\end{tabular}

\subsection{Family planning knowledge and utilization}

Almost all (97.2\%) study participants were heard about contraceptives; more than half (56.5\%) health care workers were a source of information. The majority (83.4\%) of study participants had ever used contraceptives previously, of which (53.3\%) were contraceptive users currently, nearly one third (60.0\%) of them use inject able (Table 2 ). 
Table 2 Reproductive history and services of women reproductive age group in Aykel town, North West Ethiopia, 2018 $(n=422)$

\begin{tabular}{|c|c|c|c|}
\hline Variables & Category & Frequency & Percentage \\
\hline \multirow[t]{4}{*}{ Source of Information } & Health provider & 349 & 82.7 \\
\hline & Mass-media & 155 & 36.7 \\
\hline & Friends & 146 & 34.6 \\
\hline & School & 84 & 19.9 \\
\hline \multirow[t]{2}{*}{ Ever used contraceptives } & Yes & 352 & 83.4 \\
\hline & No & 70 & 16.6 \\
\hline \multirow[t]{2}{*}{ Currently used contraceptives } & Yes & 225 & 53.4 \\
\hline & No & 197 & 46.6 \\
\hline \multirow{5}{*}{$\begin{array}{l}\text { Methods of contraceptives currently } \\
\text { used }(n=225)\end{array}$} & Inject able & 135 & 60.0 \\
\hline & Implant & 47 & 20.9 \\
\hline & Pills & 29 & 12.9 \\
\hline & IUCD & 10 & 4.4 \\
\hline & Other* & 14 & 6.2 \\
\hline \multirow{8}{*}{$\begin{array}{l}\text { Reason of not used contraceptives } \\
(n=66)\end{array}$} & I want more children & 19 & 28.5 \\
\hline & Contraceptives side effect & 16 & 24.2 \\
\hline & Poor health provider approach & 10 & 15.2 \\
\hline & My choice method not available & 8 & 12.1 \\
\hline & No one raised the issue & 5 & 1.2 \\
\hline & Services far from my house & 3 & 3.5 \\
\hline & Changed my mind & 3 & 4.5 \\
\hline & Referred to other health facility & 2 & 3.0 \\
\hline
\end{tabular}

\subsection{Obstetric history related factors}

The majority of women (88.2\%) had pregnancy previously, of which (88.8\%) pregnancies were wanted. Age women at first pregnancy ranged 21-30 years. The mean (SD) of live delivery was $2.96( \pm 1.2)$. In the previous mode of delivery, $268(81.2 \%)$ of respondents gave birth with spontaneous vaginal delivery, $68(18.8 \%)$ of the mothers were given birth with Assisted instrumental delivery (Table 3).

Table 3 Obstetric characteristics of reproductive aged women in Aykel town, Northwest Ethiopia, 2018 (n=422)

\begin{tabular}{|l|c|c|c|}
\hline \multicolumn{1}{|c|}{ Variables } & Category & Frequency & Percentage \\
\hline \multirow{2}{*}{ Gravidity } & No & 77 & 18.8 \\
\cline { 2 - 4 } & Yes & 345 & 88.2 \\
\hline \multirow{2}{*}{ Status of pregnancy n=345 } & Wanted & 268 & 88.8 \\
\cline { 2 - 4 } & Unwanted & 167 & 18.2 \\
\hline \multirow{2}{*}{ Age of first pregnancy n=345 } & $11-20$ & 178 & 51.6 \\
\hline \multirow{2}{*}{ Number of pregnancies } & $21-30$ & 77 & 18.2 \\
\cline { 2 - 4 } & 0 & 303 & 71.8 \\
\cline { 2 - 4 } & $1-4$ & 42 & 10.0 \\
\cline { 2 - 4 } & 25 & 108 & 25.6 \\
\hline \multirow{2}{*}{ Parity } & 0 & 93 & 22.0 \\
\cline { 2 - 4 } & 1 & 183 & 43.4 \\
\hline
\end{tabular}




\begin{tabular}{|l|c|c|c|}
\hline & $\geq 5$ & 38 & 9.0 \\
\hline \multirow{3}{*}{ Number of Alive children } & 0 & 107 & 25.4 \\
\cline { 2 - 4 } & $1-4$ & 119 & 28.2 \\
\cline { 2 - 4 } & $\geq 5$ & 196 & 46.2 \\
\hline \multirow{2}{*}{ Mode of delivery for the last birth (n=336) } & Spontaneous vaginal delivery & 268 & 81.2 \\
\cline { 2 - 4 } & Assisted vaginal delivery & 68 & 18.8 \\
\hline
\end{tabular}

\subsection{Prevalence of induced abortion}

The prevalence of induced abortion was $14.5 \%$ (95\%CI: 11.2 to 18.17). Of induced abortions, 52 (85.2\%) were safe induced abortion and the remaining were unsafe induced abortion. Three in four induced abortions were terminated within the first trimester. Out of total participants (38.9\%) witnessed complications of abortion of which, excessive vaginal bleeding (12.3\%), infection (9.2\%), infertility (7.1\%), and (5.2\%) menstrual disorders were the most commonly mentioned complications (Table 4).

Table 4 Abortion related characteristics of reproductive aged women in Aykel town, Northwest Ethiopia, 2018(n=422)

\begin{tabular}{|c|c|c|c|}
\hline Characteristics & Category & Frequency & Percentage (\%) \\
\hline \multirow[t]{2}{*}{ Have you ever had abortion } & Yes & 61 & 14.5 \\
\hline & No & 361 & 85.5 \\
\hline \multirow[t]{2}{*}{ Place of induced abortion } & Private health facility & 34 & 8.1 \\
\hline & Public health facility & 17 & 6.4 \\
\hline \multirow[t]{2}{*}{ Type of induced abortion $(n=61)$} & Safe induced abortion & 52 & 85.2 \\
\hline & Unsafe induced abortion & 9 & 14.8 \\
\hline \multirow[t]{3}{*}{ Method of induced abortion } & Medication & 45 & 10.7 \\
\hline & MVA & 10 & 2.4 \\
\hline & Herbal medicine & 6 & 1.4 \\
\hline \multirow[t]{2}{*}{ Know abortion complications } & No & 258 & 61.1 \\
\hline & Yes & 164 & 38.9 \\
\hline \multirow[t]{7}{*}{ Mentioned complications } & Excessive bleeding & 52 & 12.3 \\
\hline & Infection & 39 & 9.2 \\
\hline & Infertility & 30 & 7.1 \\
\hline & Menstrual disorders & 22 & 5.2 \\
\hline & Chronic pelvic pain & 11 & 2.6 \\
\hline & Imperforate uterus & 9 & 2.1 \\
\hline & Other* & 1 & 0.9 \\
\hline \multirow[t]{5}{*}{ Reasons for induced abortion $(\mathrm{n}=61)$} & Economic reason & 21 & 34.4 \\
\hline & To complete education & 18 & 29.5 \\
\hline & Health problems & 14 & 23.0 \\
\hline & Fear of my partner and family & 6 & 9.8 \\
\hline & Other** & 2 & 3.3 \\
\hline
\end{tabular}

\subsection{Factors associated with induced abortion}

Findings from binary logistic regression analysis, women's age group, marital status, maternal educational level, occupation, and ever contraceptive use, parity, knowing induced abortion complication, pregnancy status, and partner educational level were statistically associated with the induced abortion of reproductive-age women. 
Multivariate logistic regression analysis was run to control confounding effect of one variable over another variable. After adjustment age, pregnancy status, parity, ever use contraceptives, knowledge of induced abortion complication andpartner level of education were showed significantly association with induced abortion.

In multivariate logistic regression analysis, women 15-24 age groups were 3.1 times more likely induced abortion as compared to old women reproductive age groups; (AOR=3.10;95\%CI (1.116-8.543)) and women 25-34 age groups were 2.5 times more likely to induced abortion compared to older women reproductive age groups; (AOR=2.53; 95\%CI (1.067-5.973)).The odds of having unwanted pregnancies were 3 times more likely to commit induced abortion as compared to respondents having wanted pregnancy; (AOR = 3.10(1.292-7.322)). Women who had ever used contraception had 3.9 times more likely committed to induce abortion when compared with not ever used (AOR = 3.96; 95\%CI (1.612-9.709)).

Women who were Perimiparous were $63 \%$ times less likely to have had an induced abortion as compared with multiparous women; (AOR=0.37; 95\% CI ((0.164-0.823)). Women who hadn't knowledge about induced abortion complications were 2.2 times more likely to have induced abortion as compared to respondents having knowledge about induced abortion complications (AOR $=2.24(1.104-4.551)$ ). The odds of induced abortions were 3.7 times higher among women had partner with primary education (AOR =; 3.68; 95\%CI (1.082-12.528)) Table (5).

Table 5 Binary and multiple multivariate logistic regressions on different variables towards prevalence of induced abortion in reproductive age group in Aykel town, Northwest, Ethiopia, $2018(\mathrm{n}=422)$

\begin{tabular}{|c|c|c|c|c|}
\hline \multirow[t]{2}{*}{ Variables } & \multicolumn{2}{|c|}{ Induced abortion } & \multirow[t]{2}{*}{ Crud OR(95\% CI) } & \multirow[t]{2}{*}{ Adjusted OR(95\%CI) } \\
\hline & Yes & No & & \\
\hline & $61(14.5 \%)$ & $361(85.5 \%)$ & & \\
\hline \multicolumn{5}{|l|}{ Age group } \\
\hline $15-24$ & $14(19.8)$ & $123(117.2)$ & $3.19(1.452-6.954) *$ & $3.10(1.116-8.543) * *$ \\
\hline $25-34$ & $30(31.9)$ & 191(189.1) & $2.30(1.172-4.524) *$ & $2.53(0.967-5.973)$ \\
\hline$\geq 35$ & $17(9.3)$ & $47(54.7)$ & 1 & 1 \\
\hline \multicolumn{5}{|l|}{ Marital status } \\
\hline Single & $25(13.4)$ & $68(79.4)$ & $0.33(0.188-0.594)^{*}$ & $0.45(0.188-1.076)$ \\
\hline Married & $36(47.6)$ & $293(281.4)$ & 1 & 1 \\
\hline \multicolumn{5}{|l|}{ Pregnancy status } \\
\hline wanted & $10(19.1)$ & $99(89.9)$ & 1 & 1 \\
\hline unwanted & $451(41.9)$ & 189(198.1) & $2.67(1.300-4.489) *$ & $3.10(1.292-7.322)^{* *}$ \\
\hline \multicolumn{5}{|l|}{ Educational status } \\
\hline No formal education & $31(25.4)$ & $145(150.6)$ & $0.32(0.129-0.804) *$ & $0.49(0.121-1.979)$ \\
\hline Primary school & $16(11.0)$ & $50(65.0)$ & $0.26(0.096 .0 .966)^{*}$ & $0.29(0.065-1.263)$ \\
\hline Second school & $8(11.1)$ & $69(65.9)$ & $0.60(0.197-1.795)$ & $0.84(0.174-4.016)$ \\
\hline Diploma and above & $6(13.4)$ & $87(79.6)$ & 1 & 1 \\
\hline \multicolumn{5}{|l|}{ Maternal occupation } \\
\hline House wife & $25(28.3)$ & $171(167.7)$ & $2.20(0.997-4.679)$ & $0.87(0.331-2.282)$ \\
\hline merchant & $11(13.3)$ & 81(78.7) & $2.3(0.941-5.789)^{*}$ & $0.42(0.143-1.248)$ \\
\hline employee & $13(12.1)$ & 71(71.9) & $1.73(0.717-4.150)$ & $0.40(0.125-1.266)$ \\
\hline Student & $12(7.2)$ & $38(42.8)$ & 1 & 1 \\
\hline
\end{tabular}


World Journal of Advanced Research and Reviews, 2021, 12(02), 032-041

\begin{tabular}{|c|c|c|c|c|}
\hline \multicolumn{5}{|c|}{ Had ever used contraceptives } \\
\hline Yes & $42(50.6)$ & $308(299.6)$ & $2.63(1.421-4.864) *$ & $3.96(1.612-9.709) * *$ \\
\hline No & $19(10.4)$ & $53(61.6)$ & 1 & 1 \\
\hline \multicolumn{5}{|c|}{ Currently used contraceptives } \\
\hline Yes & $38(32.7)$ & $188(193.3)$ & $0.66(0.377-1.149) *$ & $0.51(0.239-1.078)$ \\
\hline No & $23(28.3)$ & $173(167.7)$ & 1 & 1 \\
\hline \multicolumn{5}{|l|}{ Parity } \\
\hline null parity & $15(15.5)$ & $92(91.5)$ & $0.89(0.435-1.691) *$ & $0.35(0.120-1.121)$ \\
\hline primipara & $19(13.7)$ & $76(81.3)$ & $0.56(0.294-1.066)$ & $0.37(0.164-0.823) *$ \\
\hline multipara & $27(31.8)$ & $193(188.2)$ & 1 & 1 \\
\hline \multicolumn{5}{|c|}{ Know induced abortion complications } \\
\hline Yes & $35(25.0)$ & $138(148.0)$ & 1 & 1 \\
\hline No & $26(36.0)$ & $223(213.0)$ & $2.18(1.255-3,771) *$ & $2.24(1.104-4.551) *$ \\
\hline \multicolumn{5}{|c|}{ Level of partner Education } \\
\hline No formal education & $26(23.1)$ & $134(136.9)$ & $0.94(0.476-1.847)$ & $1.79(0.602-5.321)$ \\
\hline Primary school & $8(13.7)$ & $87(81.3)$ & $1.98(0.805-4.858) *$ & $3.68(1.082-12.528) *$ \\
\hline Second school & $11(9.1)$ & $52(53.9)$ & $0.86(0.371-1.992)$ & $2.10(0.641-.799)$ \\
\hline Diploma and above & $16(15.0)$ & $88(89.0)$ & 1 & 1 \\
\hline
\end{tabular}

\section{Discussion}

\subsection{Finding of the study and comparison with other studies}

In this study the magnitude of induced abortion was $14.5 \%$. The magnitude of induced abortion of current study inconsistent with prior studies conducted in Harar, Eastern Ethiopia (14.4\%)[12],Guraghe Zone (12.3\%)[16],and Iran (17\%)[17]. However, this study finding was lower than studies from Ghana (21\%)[8], China (32\%)[18],Kenya (48 \%)[11], and the Amhara region referral hospitals second trimester induced abortion19\%[19]. In contrast, the finding of current is higher than a study conducted in Dabat and Adet Districts (4.8\%)[15] and Tanzania (7\%)[20]. The possible explanation for the observed difference might be due to socio-demographic characteristics, study setting, and year of study. Abortion law (legal support) differences among countries may be responsible for the observed variations. There are different rules like prohibitive, restrictive, and free rules. Ethiopia is adopted restrictive abortion law for special conditions like rape, incest pregnancy, and severe medical conditions form mother and fetus. In this study economic reasons, health problems, and partner pressure were the most common reasons for induced abortion among reproductive-aged women.

Those women who aged 15-24 years of occurrence of induced abortion were 3.1 times higher as compared to the age group $\geq 35$ years. A study was done in Iran [5] also showed the same result in which women with induced abortions were significantly within younger age groups. This might be due to the fact that women at this age group were economically dependent on their parents, in an unstable marital relationship, and limited knowledge and access for family planning. This finding was supported by studies conducted in Tanzania and northwest Ethiopia.

This study revealed that women who had ever unwanted pregnancy were three times a significant positive association with induced abortion compared with women who have wanted pregnancy. This finding is in line with otherstudies conducted in Kenya[11] and in Ethiopia[21]. The immediate explanation for this is that a woman seeking induced abortion usually has unplanned and unwanted pregnancy which in turn is related to a lack of wide spread information about family planning services and its utilization. 
Women who have not ever used contraceptives were 3.9 times more likely to have induced abortion as compared to those who ever used contraceptives. This is due to the fact one of the purposes of contraceptives is limiting unwanted and unplanned pregnancies and births. Women who were lenient to use contraceptive was at high risk of getting pregnant, which ultimately led to induced abortion. This finding was supported by other studies [10].

The present study showed that women who were Perimiparous women were less likely to have had an induced abortion when compare with multiparous women; this evidence was supported by studies conducted in Ethiopia [5, 22, 23].

According to this finding, the odds of having induced abortion were 2.2 times greater in women not having knowledge about induced abortion complications than those who have knowledge induced abortion complications. These findings in linewithstudy in Kenya[13] and in Gondar Ethiopia[24]. The possible explanations, participants who had not enough knowledge repeating doing induced abortion and they may use it as family planning.

Partner's educational level primary school women had more likely undergo induced abortion as compared with women partners had Diploma and above educational level. This evidence was supported by a study was done in Ghana[25], on this study women with induced abortions were positively associated with partners' level of education.

\section{Limitations}

This study shares the limitations of cross-sectional studies and hence may not be possible to establish a temporalcauseeffect relationship between adverse birth outcomes and explanatory variables. Besides, as the study is that since abortion is a sensitive issue and legally restricted in Ethiopia, patient interviews may introduce social desirability bias which may result in under-reporting.

\section{Conclusions}

This study revealed that the magnitude of induced abortion was high. Being younger age, unwanted pregnancy status, had not ever used contraceptive, and knowing induced abortion complications were positively associated with induced abortion, while in contrast the number of parities was negatively associated with induced abortion. Therefore, induced abortion intervention like contraception provision need to focus young age group and improving the awareness of women on induced abortion complication is essential to avoid the habit of using induced abortion as a means of family planning for limiting and spacing birth.

\section{Compliance with ethical standards}

\section{Acknowledgments}

We would like to acknowledge Teda Health Sciences College for giving us this opportunity to prepare this research thesis and Ethiopia midwife association for this opportunity and funding. Most of all we extend our deepest gratitude to the study participants for their time and commitment.

\section{Disclosure of conflict of interest}

The authors declared that they have no competing interests.

\section{Statement of ethical approval}

Ethical clearance was obtained from the Ethics and Institutional Review Board Committee (IRB) of the Amhara Regional Health Bureau. Supportive letter and permission obtained from respective bodies. Before data collection interviewers clearly explained the purpose and objective of the study and informed verbal consent were taken from each participant. Verbal informed consent used was approved by the IRB Amhara Regional Health Bureau.

\section{Statement of informed consent}

Verbal consent was used because of the low literacy levels in the community as well as some participants are uncomfortable signing form. Those participants who aged 15-17additional parental (legal guardian) written consent was also obtained. Confidentiality was kept by making interviews in separate places and any information provided during the data collection procedure was anonymous. 


\section{Availability of data and materials}

Data generated from this study will not be shared. This is to protect and secure the confidentiality of study participant's information due to the sensitive nature of the data. The data will only be shared with a reasonable request from the corresponding author.

\section{Funding}

The study was funded by the Ethiopia midwife association. The funder has no role in study design, data collection, and analysis, interpretation of data, the decision to publish, or preparation of the manuscript.

\section{Authors' contributions}

AM conceived the study equally participated in the design, data collection, statistical analysis, and writing-up of the manuscript. AM author read and approved the final manuscript.

\section{Abbreviations}

AOR: Adjusted Odds Ratio, CI: Confidence Interval, EDHS: Ethiopia demography health survey, EPI-INFO: Epidemiological Information, ETB: Ethiopian Birr, MVA: Manual Vacuum Aspiration, NGO: Non-Governmental Organization, OR: Odds Ratio, SD: Standard Deviation, SPSS: Statistical Package for Social Science, UNDP: United nation Development for Population, WHO: World Health Organization

\section{References}

[1] C, R., Discursive Constructs of Abortion amongst a Group of Male and Female Students at the University of the Witwatersrand. BioMed research international, 2013.

[2] Kumar A, H.L., Mitchell EM, Conceptualizing abortion stigma. Cult Health sex, 2009. 11: 625-39.

[3] Systematic review study on abortion. lancet 2016.

[4] WHO, Safe and Unsafe Induced Abortion Global and Regional Levels. World Health Organization, Geneva, Switzerland, 1995-2008.

[5] Azar Ranji, M., Induced Abortion in Iran: Prevalence, Reasons, and Consequences. Journal of Midwifery \&Women's Health,www.jmwh.org, 2012. 57: p. 482-488.

[6] S, A., Views of women about accessibility of safe abortion care services in addis ababa, Ethiopia. BMC Pregnancy and Childbirth, 2013.

[7] Berrer, M., Making abortion safe; matter of good public health policy and practice. international journal of public health, 2000. 78(5): p. 56-570.

[8] Charity Vm, E.O.M., Factors Associated with Induced Abortion among Women in Hohoe, Ghana. African Journal of Reproductive Health December 2010. 14(4):115.

[9] Elias Senbeto, G.D., Nuru Ab, Prevalence and associated risk factors of Induced Abortion in northwest Ethiopia. Ethiop.J.Health Dev, 2014.

[10] Gezahegn T, M.T., Agumasie S, Induced Abortion and Associated Factors in Health Facilities of Guraghe Zone, Southern Ethiopia. Hindawi Publishing Corporation Journal of Pregnancy, 2014. 2014: p. 8.

[11] Ruvani T, F.M., Kelli Stidh,etail Women's experiences with unplanned pregnancy and abortion in Kenya. PLOS ONE | https://doi.org/10.1371/journal.pone.0191412 2018.

[12] Fantahun, S.W.a.M., Unintended pregnancy and induced abortion in a town with accessible family planning services in Harar in eastern Ethiopia. Ethiopian Journal of Health Development, 2006. 20 p. pp. 79-83

[13] Shukri FM, C.I., Ann M,etil, The estimated incidence of induced abortion in Kenya. BMC Pregnancy and Childbirth, 2015. 5(185).

[14] WHO, Demographic and Health Survey. 2016.

[15] Elias S, G.D., Nuru A,etail, Prevalence and associated risk factors of Induced Abortion in northwest Ethiopia. BMC Pregnancy and Childbirth, 2016. 
[16] Tesfaye, G., Hambisa, Mitiku Teshome,Semahegn, Agumasie, Induced abortion and associated factors in health facilities of Guraghe zone, southern Ethiopia. BMC Pregnancy and Childbirth, 2014. 2014.

[17] Erfani, A., Induced abortion in Tehran, Iran: estimated rates and correlates. International Perspectives on Sexual \& Reproductive Health, 2011.37(3).

[18] Gao, G.P., et al., Prevalence and associated factors of induced abortion among rural married women: A crosssectional survey in Anhui, China. Journal of Obstetrics and Gynaecology Research, 2015. 41(3): p. 383-391.

[19] Mulat, A., et al., Induced second trimester abortion and associated factors in amhara region referral hospitals. BioMed research international, 2015. 2015.

[20] Heidi S, V.F., Charlotte W, Induced abortion, pregnancy loss and intimate partner violence in Tanzania. BMC Pregnancy and Childbirth, 2012.

[21] Tesfaye, G., Induced Abortion and Associated Factors in Health Facilities of Guraghe Zone, Southern Ethiopia. Hindawi Publishing Corporation, 2014.

[22] Elias Senbeto, G.D., Nuru Abesno,etail Prevalence and associated risk factors of Induced Abortion in northwest Ethiopia. Ethiop.J.Health Dev, 2005.

[23] etal, G.T., Induced abortion and associated factors in health facilities of guraghe zone, southern Ethiopia. Hindawi Publishing Corporation, 2014.

[24] Mohammed Oumer, A.M., Prevalence and Associated Factors of Induced Abortion among women of reproductive age Group in Gondar Town, Northwest Ethiopia. Science Journal of Public Health, 2019. 7(3): 66-73.

[25] H.M. Schwandt, A.A.C., K. A. Danso, R. M. K. Adanu, A comparison of women with induced abortion, spontaneous abortion and ectopic pregnancy in Ghana," Contraception M. J. Hindin, 2011. 84, no. 1 p. pp. 87-93. 